\title{
Tiled roofs air permeability: experimental and numerical investigation
}

\author{
Eleonora Baccega ${ }^{1,},{ }^{*}$ Michele Bottarelli ${ }^{1}$, and Giovanni Zannoni ${ }^{1}$ \\ ${ }^{1}$ Department of Architecture, University of Ferrara, via Quartieri 8, 44121 Ferrara, Italy
}

\begin{abstract}
The construction sector accounts for more than one-third of the global energy consumption. Ventilated roofs and facades are among the adopted strategies to improve the efficiency of the building envelope: air flowing in cavities under the cladding layer, in fact, is particularly effective in hot summers for the reduction of the incoming heat flow due to solar radiation. Regarding roofs, satisfying results were obtained through the realization of a $5-10 \mathrm{~cm}$ air gap under the covering layer which allows better thermal performances of the roof and a reduction of the energy consumption for air conditioning. Although most of products and techniques applied are based on the assumption that air enters only from the eaves line and exits at the ridge one, it is demonstrated that in case of discontinuous mantles, a great contribution derives from air entering from the overlaps. As a matter of fact, air entering from the eaves line is strictly dependent on the wind direction and benefits are evident only when the wind is perpendicular. In all the other cases, buoyancy forces due to air heating under the mantle cannot provide such a consistent contribution. Tiles overlaps' air permeability allows the wind to enter from multiple directions with consequent greater ventilation of the substrate. Experimental research regarding the performances of pitched tiled roofs was conducted at the TekneHub laboratory of the University of Ferrara and the results are here presented. The tests carried out aimed at investigating the behaviour of different configurations of tiled roofs both from a thermal and an energetic point of view. Three configurations were compared: one was a completely sealed roof (sealed), one had sealed eaves and ridge lines but unsealed tiles overlaps (laid) and the last one was a ventilated roof (vented). The comparison between the sealed and the ventilated roof confirmed the improvement of the performances when in presence of an air cavity. The ventilated roof was then compared to the laid roof to assess the actual contribution of the air permeability of the tiles, and results clearly showed a great contribution, even in case of low wind.
\end{abstract}

\section{Introduction}

The environmental impact is among the most discussed issues, especially in building and construction sector, which accounts for more than one-third of the global energy consumptions [1]. With an ever-changing life style and always higher living standards,

* Corresponding author: eleonora.baccega@unife.it 
energy consumption related to buildings is continuously increasing. However, the building's energy demand is strictly connected to the efficiency of its envelope [2]. Many are the applicable technologies to couple indoor comfort and reduced environmental impact, both on new buildings as well as on existing ones, among which there is the adoption of ventilated surfaces.

Ventilated roofs are particularly effective in hot climates, such as the Mediterranean one, as they allow a reduction of the incoming heat flux in summer [3] and creating an insulating layer of air around the building's inner shell in winter [4]. Natural ventilation gained more and more attention as a potential technology for minimizing energy consumption suitable for all those contexts characterized by heights restrictions or refurbishment limitations [5]. Preventing the heat transfer through the building envelope instead of cooling the building from the penetrated heat is effective not only from the environmental point of view, as reduces the cooling power consumption, but also from the economic one concerning the initial investment as well as the life cycle expense [6]. The efficacy of ventilated roofs was assessed by means of laboratory tests $[7,8]$ as well as full scale models. Even though it is still frequently assessed that air enters from the eaves line and leaves at the ridge one, it is demonstrated that in case of discontinuous mantles (i.e., clay tiles) air enters and leaves even from the tiles' overlapping, thus enhancing the ventilation under the cladding layer, in the so-called Above Sheathing Ventilation (ASV), providing an additional network of airflow paths $[9,10]$.

In this paper, the results of an experimental research on the performances of different configurations of roof, with focus on mantle's air permeability, are presented.

\section{Methodology}

The research here proposed is based on experimental tests carried out during summer to evaluate the effect of the air permeability on a tilted roof covered by standard Portuguese clay tiles.

Exploiting the experience gained in previous researches [8, 10, 11], the collected data are meant to be used to calibrate a numerical model with the software COMSOL Multiphysics which aim will be the implementation of an equivalent roof made of a porous medium able to simulate the behaviour of a tiled ventilated roof with a simplified geometry therefore reducing the simulating times.

\subsection{Experimental set up}

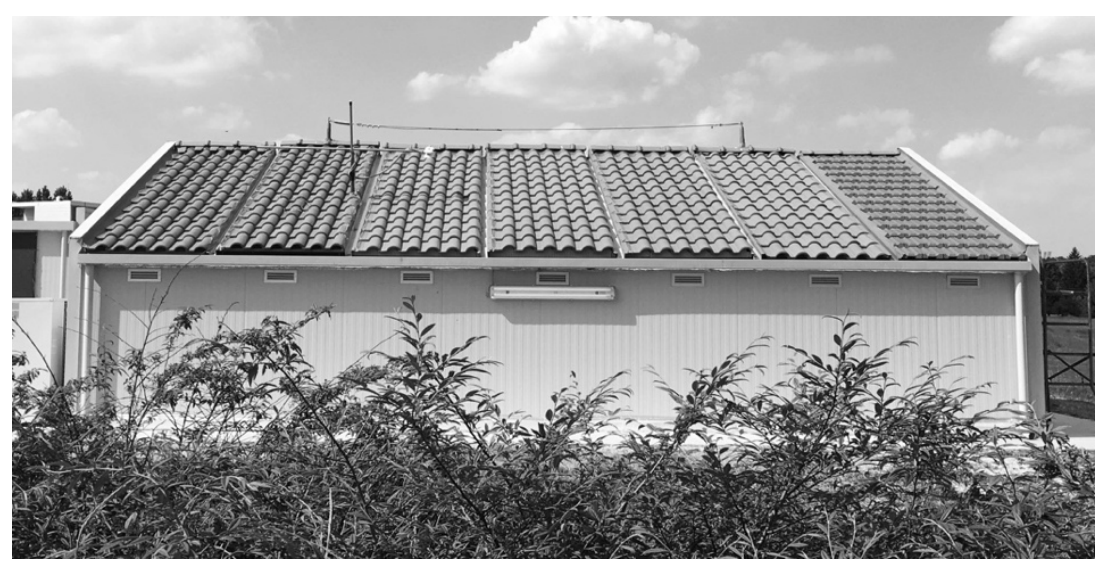


Fig 1. Experimental building (mock up) at the TekneHub Laboratory of the University of Ferrara.

The experimental tests were carried out at the TekneHub Laboratory of the University of Ferrara in an experimental building (mock up, Figure 1) which was realized for the European project LIFE Climate Change Adaptation - HEROTILE (High Energy savings in building cooling by ROof TILEs shape optimization toward a better above sheathing ventilation). The building, with a rectangular $10 \mathrm{~m} \mathrm{x} 8 \mathrm{~m}$ plan, is made of five adjacent independent test rooms and two guard rooms on the sides that ensure the same conditions in all the test rooms. The temperature in each room was kept controlled by means of a digital thermostat that regulated a fan coil. The roof is tilted with two symmetrical pitches inclined by $20^{\circ}$ and north-south oriented. Moreover, in order to avoid any interference from the surrounding that may affect the performances, the mock up was built on an embankment about $2 \mathrm{~m}$ above the ground level. The steel structure building was clad with sandwich panels both for the perimeter walls as well as for the internal ones while, as regards the roof, a wooden deck covered by a waterproof polyolefin membrane was arranged as support for each configuration investigated.

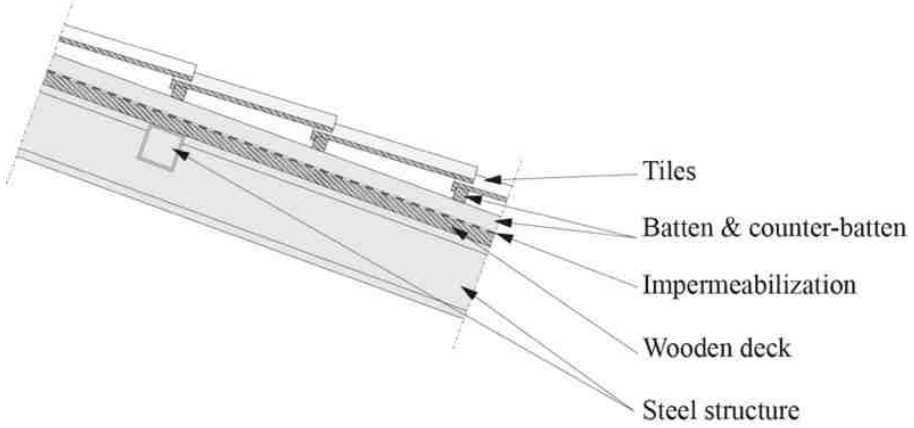

Figure 1. Ventilated roof section.

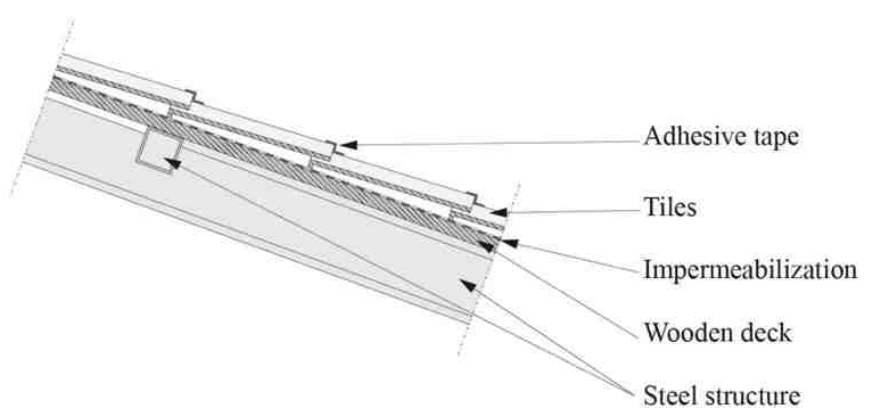

Figure 2. Sealed roof section. 


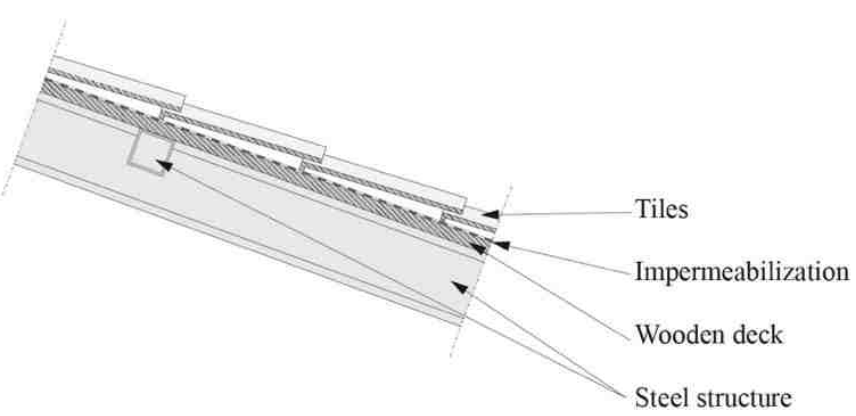

Figure 3. Laid roof section.

In the frame of a wider research, the performances of different roofs covered with standard Portuguese clay tiles were monitored in order to assess the effectiveness of the air permeability of a discontinuous mantle. A preliminary test was carried out by comparing the performances of a ventilated roof (Figure 2) with a completely sealed one (Figure 3). The former had a standard wooden batten and counter-batten structure that shaped a $4+3$ air cavity with expanded metal on the eaves line, the latter had tiles directly positioned on the deck with no support, eaves and ridge lines sealed with polyurethane foam and tiles' overlaps closed by means of a waterproof adhesive tape. The results obtained were used as benchmarks for the subsequent test, in which the actual contribution of the air permeability of the mantle was investigated by comparing the same roofs as the previous test, but with the waterproof adhesive tape removed from the tiles' overlaps. In this last configuration, tiles were directly positioned on the deck with no sealant on the overlaps and the eaves and ridge lines were kept completely closed: air could enter or leave the ASV only through the overlaps (Figure 4). This configuration was conventionally called laid.

\subsection{Monitoring system and data acquisition}

Several sensors were installed for the monitoring activity. For what concerns the boundary conditions, a weather station outside the laboratory collected data about solar radiation, air temperature and humidity, wind speed and direction with a time step of 15 minutes. Additional sensors were installed for more accurate measures: an inclined pyranometer, parallel to the roof south pitch, was installed above the mock up roof to measure the solar radiation, a RTD Pt100 was installed right outside the north wall of the mock up to measure the air temperature and four cup anemometers were positioned at different heights $(1.50-2.50-4.00-6.00 \mathrm{~m})$ to estimate the wind profile. Regarding each test room, an accurate monitoring system was arranged and sensors were installed in different positions of the pitches as well as between the layers. On both the north and the south pitch temperature sensors and anemometers were installed. As regards temperatures, T type thermocouples (accuracy: $0.5 \mathrm{~K}$ ) measured the temperature of the tile intrados (Tile temperature, Tt) while RTDs Pt100 (accuracy: $0.5 \mathrm{~K}$ ) measured the temperature of the air in the cavity (ASV temperature, Ta), the temperature of the extrados and intrados of the wooden deck (Deck temperature and Ceiling temperature, respectively) and inside the room (Room temperature, Tr). As regards anemometer, several hot-wire and hot-films anemometers (accuracy: 0.05 $\mathrm{m} / \mathrm{s}$ ) were positioned at different sections of the pitches in the air cavity to measure the velocity. In addition, a heat flux meter (uncertainty of calibration: 3\%) was positioned in the center of each south pitch, on the inner side of the wooden deck (HF) to quantify the heat flux entering from the roof. In Figure 5 an axonometric view of one of the rooms and a detail of the sensors' position and nomenclature are depicted. 
All the above-mentioned sensors were connected to a datalogger (DataTaker DT85 series 4) which acquired data with a time step of one minute and saved them every 30 minutes in a connected computer in .csv format. Lastly, thermal energy meters were installed on each fan coil to monitor the energy requirement for cooling of each room and, through a M-bus gateway, were connected to the same computer as the datalogger with a time step of 5 minutes.

\section{Results and discussion}

As the tests were not carried out at the same time, two similar periods of three consecutive days were selected in terms of air temperature, solar radiation, wind speed and direction and results are hereafter presented.

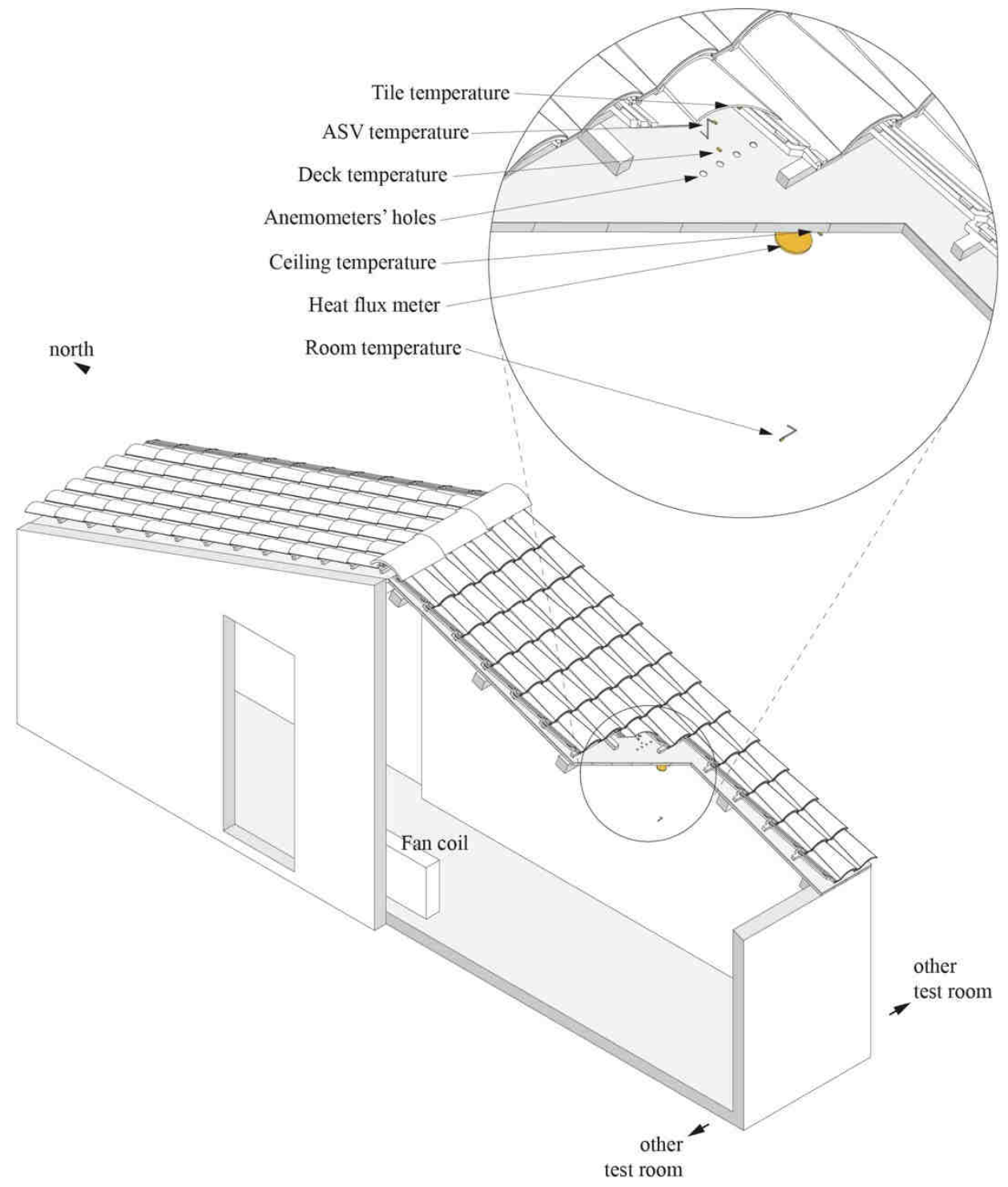

Figure 4. Axonometric view of a test room with a detail of the sensors' position and nomenclature. 


\subsection{Vented (V) vs Sealed (S) roof}

As depicted in Figure 6 and Figure 7, during the selected period of the first test (August 2019), the air temperature fluctuated between $20^{\circ} \mathrm{C}$ at night and $34^{\circ} \mathrm{C}$ during the day, with a solar radiation that reached peaks of nearly $950 \mathrm{~W} / \mathrm{m} 2$. The average wind speed was of about $1 \mathrm{~m} / \mathrm{s}$ with peaks of $1.5 \mathrm{~m} / \mathrm{s}$ in the first day and directions were mainly east and southeast, with peaks from west. Among the several sensors used, those positioned in the middle of the south pitch (depicted in Figure 4) were considered as the most representative of the average behaviour of the roof. In Figure 8 are depicted the temperature of the tile (Tt) and the temperature and velocity of the air in the ASV (Ta, Va), while in Figure 9 are depicted

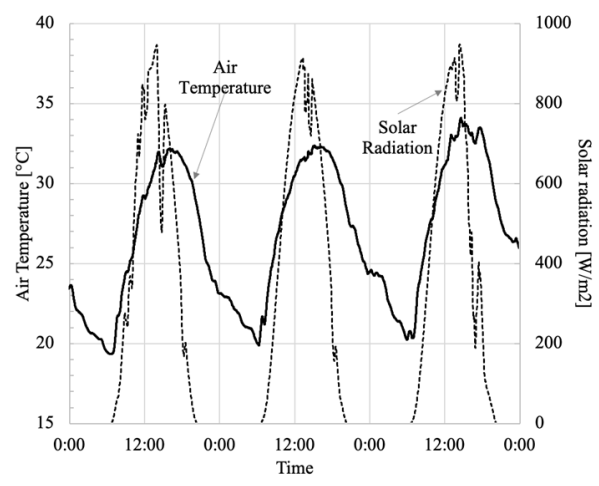

Figure 5. Test 1. Air temperature and solar radiation.

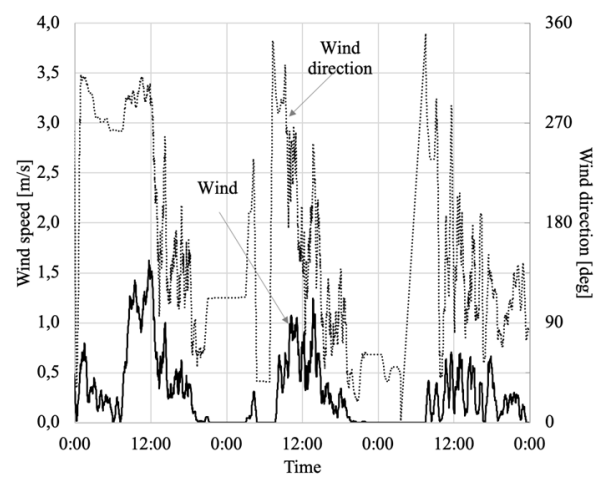

Figure 6. Test 1. Wind speed and direction $(0$ corresponds to north and directions are read clockwise).

the room temperature (Tr) and the heat flux (HF) of both the ventilated roof as well as of the sealed one. Given the positioning of the heat flux meters, negative values correspond to incoming heat fluxes. During the hottest hours of each day, the temperature of the tile of the sealed roof was of nearly $55^{\circ} \mathrm{C}$, with a peak of $60{ }^{\circ} \mathrm{C}$ on the third day, and was about $4 \mathrm{~K}$ hotter than the ventilated one. For what concerns the temperature of the air in the ASV, in the sealed roof the maximum temperatures recorded were between $50{ }^{\circ} \mathrm{C}$ and $55^{\circ} \mathrm{C}$, much higher than those of the ventilated one, with peak differences of $9 \mathrm{~K}$ that correspond to more than $15 \%$. Analogous considerations can be made on the incoming heat flux, where differences of about $10 \mathrm{~W} / \mathrm{m} 2$ are visible during the hottest hours of the day, with a peak of $14 \mathrm{~W} / \mathrm{m} 2$ on the first day of the selected period. Given that the incoming heat flux of the sealed roof reached peaks between $40 \mathrm{~W} / \mathrm{m} 2$ and $50 \mathrm{~W} / \mathrm{m} 2$, the reduction recorded in the ventilated roof was of about 20\%. As regards the air velocity in the ASV, in Figure 8 the historical series of the collected data is depicted. As expected, under the sealed roof air was completely still, while under the ventilated one air was moving, although the registered values were very low and at the limit of the sensors' precision. This, however, is due to the low wind speed that characterized the period here considered. In Figure 10 the values were then classified according to the wind direction. If air entered only from the eaves line, higher velocity in the ASV would be expected with wind from the south. On the contrary, from the collected data, wind direction seems to be not very relevant and for each direction a reduction factor between 0.1 and 0.2 is noticed. More specifically, with wind directions between $45^{\circ}$ and $135^{\circ}$ (north-east to south-east) the reduction factor is slightly higher and around 0.2 , while in case of wind directions between $180^{\circ}$ and $360^{\circ}$ the reduction factor is around 0.1 . Considering the orientation of the mock up, the overlaps between adjacent tiles face east, 
therefore the higher reduction factor can be due to the greater ease of air to enter. Lastly, some considerations were done for what concerns the energy requirement for cooling. In Figure 11 are depicted in detail the room temperature and the energy required for cooling for one of the days of the selected period, more specifically the second one. The fluctuations in the room temperature are due to the switching on and off of the fan coils. In the room under the sealed roof the fan coil was switched on by the digital thermostat 22 times, while in case of the ventilated roof it happened 19 times. Analysing the data collected by the thermal energy meters, the energy required to maintain the set point temperature with the sealed roof was of nearly $394 \mathrm{Wh} / \mathrm{m} 2$, while with the ventilated one it was of $330 \mathrm{Wh} / \mathrm{m} 2$. Therefore, the reduction in the energy requirement is of about $16 \%$.

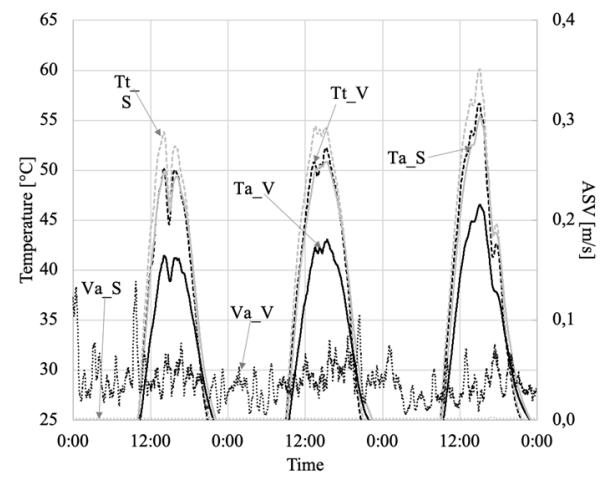

Figure 7. Test 1. Tile temperatures (Tt), ASV temperatures (Ta) and ASV velocity (Va).

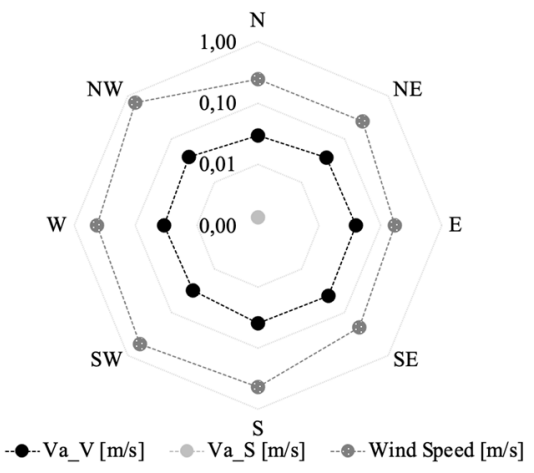

Figure 9. Test 1. Overall ASV average velocity in the middle of the south pitch for different wind directions.

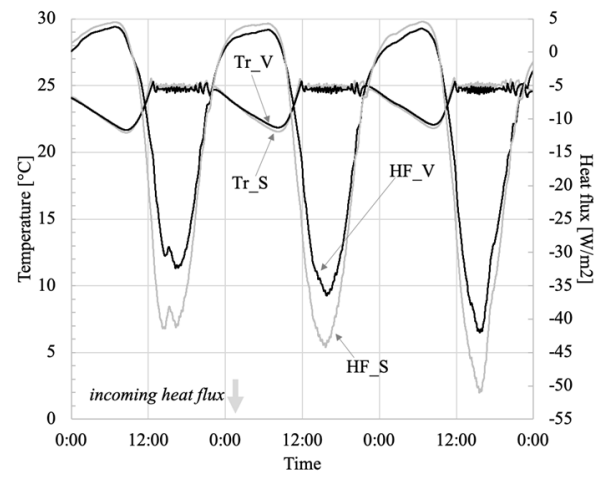

Figure 8. Test 1. Room temperature (Tr) and heat flux (HF).

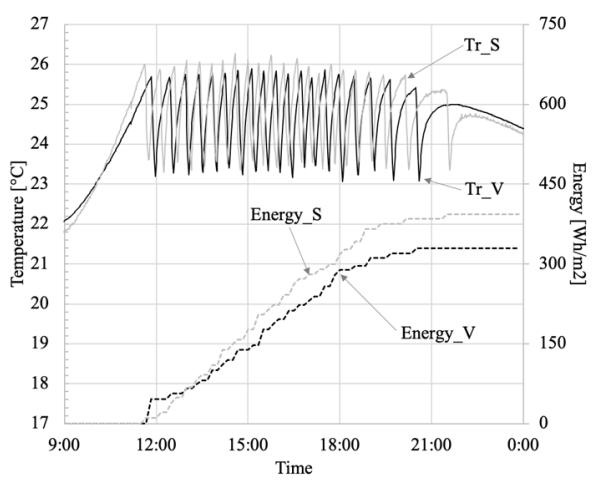

Figure 10. Test 1, day 2. Room temperature (Tr) and energy required for cooling.

\subsection{Vented (V) vs Laid (L) roof}

As above mentioned, after having compared the ventilated to the sealed roof, the sealant on the tiles' overlaps was removed. In this third configuration, named laid (L), tiles were directly positioned on the wooden deck and the eaves and the ridge lines were sealed with polyurethane foam. As the previous test, a period of three consecutive days (August 2019) 
was selected and the boundary conditions are depicted in Figure 12 and Figure 13. The air temperature was slightly higher than the first test, and fluctuated between $23{ }^{\circ} \mathrm{C}$ at night and $36{ }^{\circ} \mathrm{C}$ during the day, while the solar radiation was quite similar and reached peaks of 950$1000 \mathrm{~W} / \mathrm{m} 2$. The average wind speed was slightly lower than $1 \mathrm{~m} / \mathrm{s}$ with peaks of $1.6 \mathrm{~m} / \mathrm{s}$ on the second day and the direction was mainly south-east with peaks from west. In Figure 14 are depicted the temperature of the tile and the temperature and velocity of the air in the ASV while in Figure 15 the room temperature and the heat flux through the roof. As depicted, the room set point temperature was the same of the first test, that was $26{ }^{\circ} \mathrm{C}$. In this case, the differences between the two configurations decreased. During the hottest hours, in the laid roof the temperature of the tile reached peaks of $57-58{ }^{\circ} \mathrm{C}$ in the first and second day and of nearly $53{ }^{\circ} \mathrm{C}$ in the third one, while in the ventilated roof the temperature of the tile was

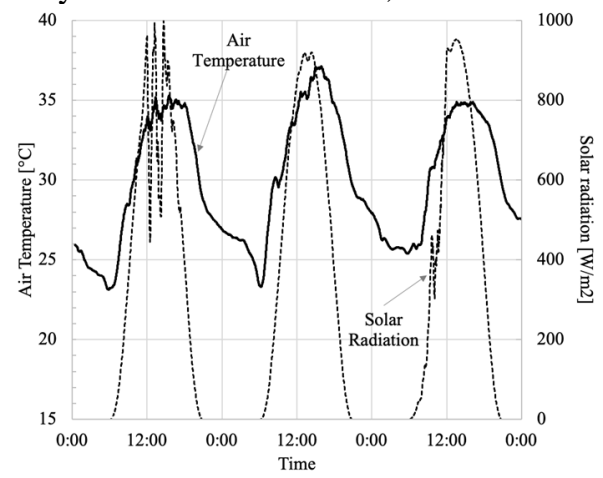

Figure 11. Test 2. Air temperature and solar radiation.

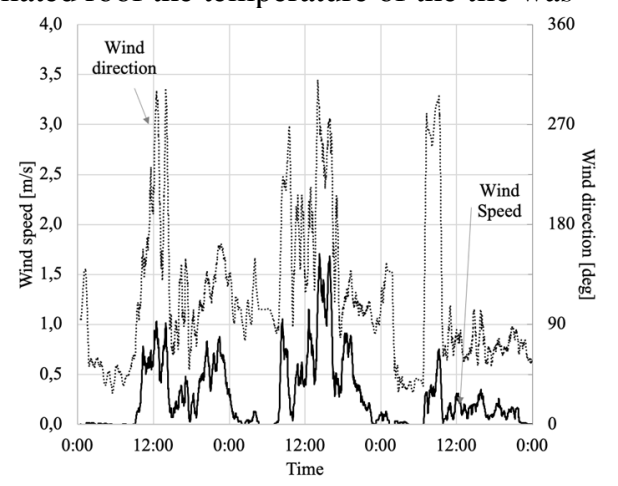

Figure 12. Test 2. Wind speed and direction $(0$ corresponds to north and directions are read clockwise).

slightly lower on the first two days and nearly $3 \mathrm{~K}$ higher on the third day. As regards the temperature of the air in the ASV, in the ventilated roof the values reached peaks of nearly $47{ }^{\circ} \mathrm{C}$ on each of the selected days. On the first and second day the temperature in the laid roof was about $5.5 \mathrm{~K}$ higher, while in the third day the difference was of $3 \mathrm{~K}$. On average, the peaks difference reached corresponds to a reduction of the temperature of the air in the ASV in the ventilated roof of nearly $10 \%$. As regards the heat flux, the peaks reached in the ventilated roof were between $40 \mathrm{~W} / \mathrm{m} 2$ and $45 \mathrm{~W} / \mathrm{m} 2$ while in the laid one the peaks were slightly higher, with differences up to $6 \mathrm{~W} / \mathrm{m} 2$ on the first and the second day and of $3 \mathrm{~W} / \mathrm{m} 2$ on the third one. On average, the peak reduction of the incoming heat flux in the ventilated roof was of $10 \%$.

Concerning the air velocity in the ASV, in Figure 14 is depicted the historical series of the collected data. Air under the laid roof was moving but, as for the previous test, the wind speed was quite low (a common condition in Ferrara) and so the values for the air velocity in the ASV were at the limit of the sensors' precision. In Figure 16 these values were classified according to the wind direction. Compared to the first test, in which the wind speed was quite homogeneous from all the directions, during the three days selected for the second test the wind speed in case of wind from north and north-east were lower than from the other directions. For what concerns the ventilated roof, a reduction value of about 0.1 was confirmed in case of wind directions between $180^{\circ}$ and $315^{\circ}$ (north-west), while in all the other cases the wind speed was too low to estimate a reduction factor. However, it is interesting to see that the air velocity in the ASV in the ventilated roof and in the laid one was quite the same in case of wind from east and south-east, so when wind direction was from the tiles' overlaps. In case of wind from other directions, the velocity in the ASV of the laid roof was lower. 
Lastly, as regards the energy requirement for cooling, in Figure 17 are depicted in detail the room temperature and the energy required for cooling for the first day of the selected period. In the room under the laid roof the fan coil was switched on 29 times, while in case of the ventilated roof 28 times. From the data collected by the thermal energy meters, the energy required to maintain the set point temperature with the sealed roof was of about 463 $\mathrm{Wh} / \mathrm{m} 2$, while with the ventilated one it was of $452 \mathrm{Wh} / \mathrm{m} 2$, which correspond to a slight reduction, equal to $2.3 \%$.

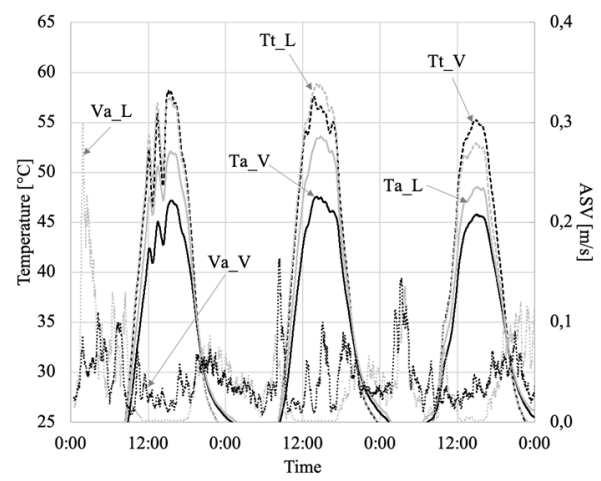

Figure 13. Test 2. Tile temperatures (Tt), ASV temperatures (Ta) and ASV velocity (Va) measured in the middle of the south pitch.

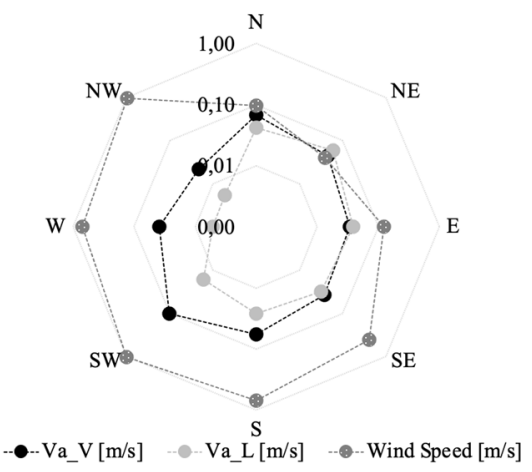

Figure 15. Test 2. ASV average velocity in the middle of the south pitch for different wind directions.

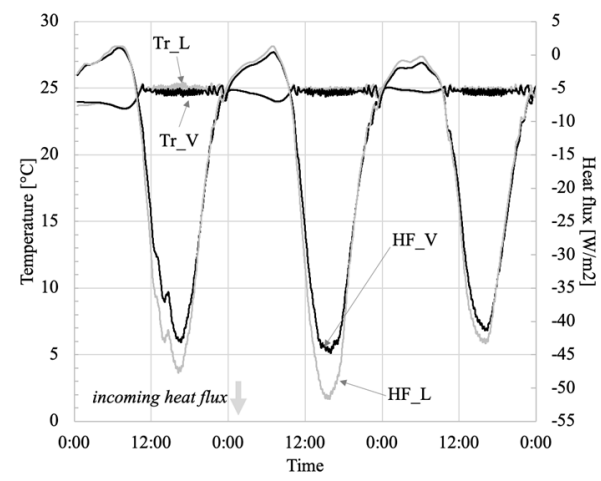

Figure 14. Test 2. Room temperature ( $\mathbf{T r})$ and heat flux (HF).

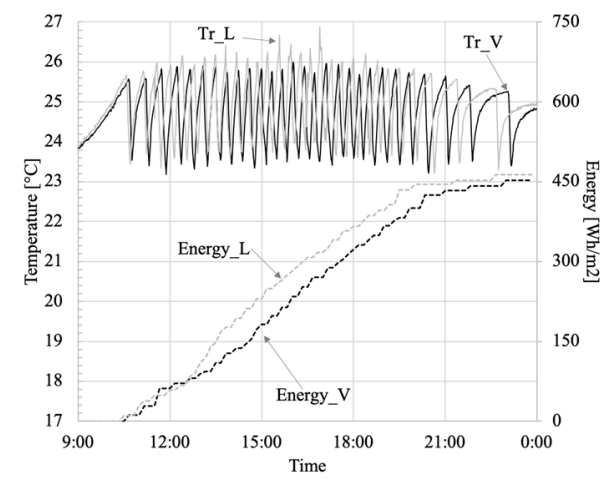

Figure 16. Test 2, day 1. Room temperature (Tr) and energy required for cooling.

\subsection{Extension of the results}

In the above reported data, clear evidence of the contribution of the tiles' permeability emerges. The differences between the three realized configurations are evident in the hottest hours of the day, while with low solar radiation and air temperature the behaviours of the roofs are almost identical. For this reason, a better detailed comparison was made between the three roofs, considering a longer period than the previous ones but selecting days with 
comparable boundary conditions and analysing data only in the interval 12:00-15:00. As the mock up envelope had very low inertia, the selected time interval was exhaustive to consider the period in which the external conditions were more critic and the energy requirement was greater. In Table 1 are depicted the average values for solar radiation, air temperature and wind speed for both the periods: period 1 and period 2 are the extensions of test 1 and test 2, respectively.

The average air temperature in the first period was of nearly $33{ }^{\circ} \mathrm{C}$, while in second one it was slightly higher and about $33.5^{\circ} \mathrm{C}$. The solar load was almost the same and around 800 $\mathrm{W} / \mathrm{m} 2$, as regards the wind speed, in the first period the average was of $0.9 \mathrm{~m} / \mathrm{s}$ and in the second one it was of $1.3 \mathrm{~m} / \mathrm{s}$.

Table 1. Average boundary conditions (interval 12:00-15:00).

\begin{tabular}{|c|c|c|}
\hline Average boundary conditions & Period 1 & Period 2 \\
\hline Air Temperature & $32.9^{\circ} \mathrm{C}$ & $33.5^{\circ} \mathrm{C}$ \\
\hline Solar Radiation & $812 \mathrm{~W} / \mathrm{m}^{2}$ & $816 \mathrm{~W} / \mathrm{m}^{2}$ \\
\hline Wind Speed & $0.9 \mathrm{~m} / \mathrm{s}$ & $1.3 \mathrm{~m} / \mathrm{s}$ \\
\hline
\end{tabular}

In Figure 18 the average values in terms of tile temperature, air in the ASV temperature, heat flux and energy for cooling are depicted, divided according to the monitoring period. Comparing the ventilated and the sealed roof, great reduction due to the air flowing are visible. The average temperature of the intrados of the tile was $3 \mathrm{~K}$ lower, equal to $5.6 \%$, while as regards the air in the ASV the difference was much greater as it was of $8.3 \mathrm{~K}$, corresponding to a reduction of $16.2 \%$. Concerning the incoming heat flux, the difference between the average values was of nearly $10 \mathrm{~W} / \mathrm{m} 2$, corresponding to $21.6 \%$ and this was then reflected to the energy required for cooling, where a reduction of more than $24 \%$ in the ventilated roof is evident. On the other hand, considering the comparison between the ventilated and the laid roof the differences are consistently reduced, even by more than $50 \%$. The temperatures of the intrados of the tile were the same and those of the air in the ASV differed for $4 \mathrm{~K}$, corresponding to $8.7 \%$. As regards the heat flux, the difference between the average values was of less than $4 \mathrm{~W} / \mathrm{m} 2$, equal to $11.3 \%$, while energy required for cooling was reduced by $9.8 \%$. 


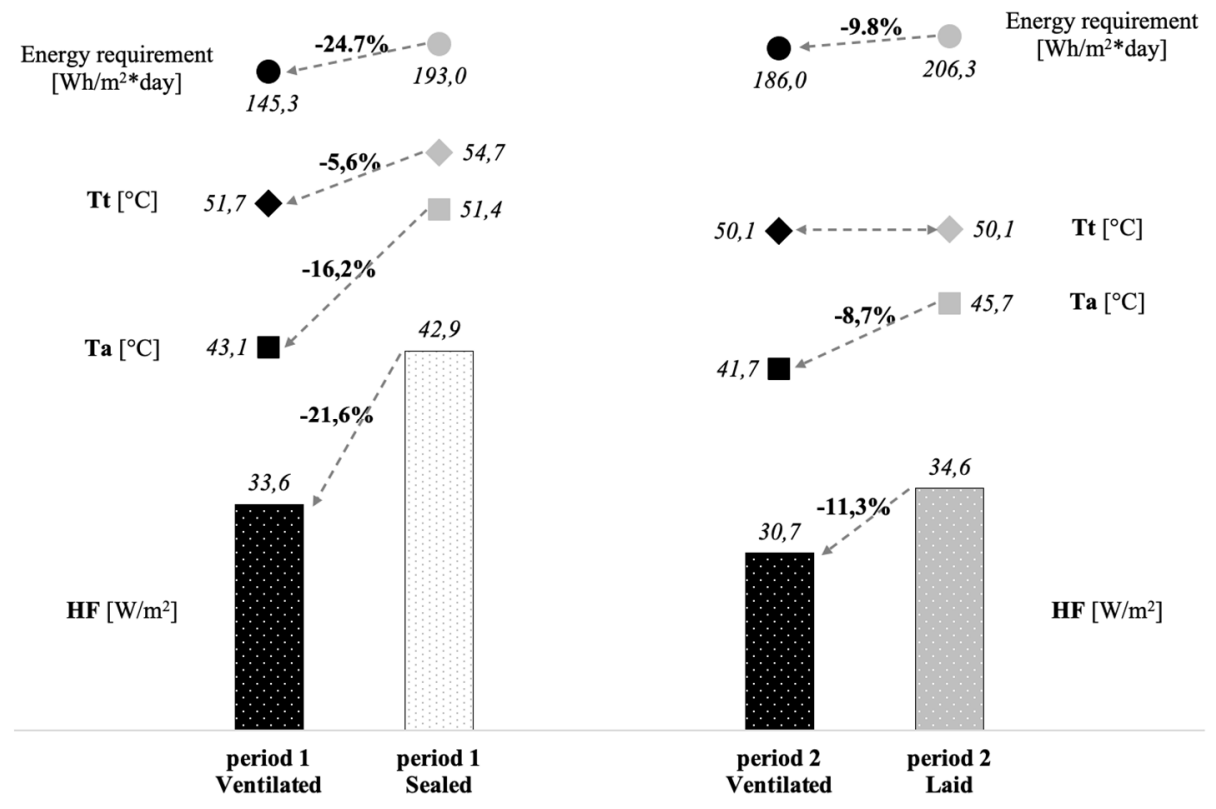

Figure 17. Average values (interval 12:00-15:00) for period one and period 2.

In Table 2 the above-described differences are normalized and from these comparisons it appears that the air permeability of the mantle accounts for about $50 \%$ of the enhancement a ventilated roof can bring.

Table 2. Reduction for laid and ventilated roof, compared to sealed one.

\begin{tabular}{|c|c|c|}
\hline Reduction, compared to sealed roof & Laid & Ventilated \\
\hline Tile temperature & $-5.6 \%$ & $-5.6 \%$ \\
\hline ASV temperature & $-8.2 \%$ & $-16.2 \%$ \\
\hline Heat Flux & $-11.7 \%$ & $-21.6 \%$ \\
\hline Energy required & $-16.5 \%$ & $-24.7 \%$ \\
\hline
\end{tabular}

\section{Conclusions}

The experimental research carried out at the TekneHub Laboratory of the University to Ferrara aimed at investigating more in detail the behaviour of a ventilated roof and assessing the actual contribution of the air permeability of a discontinuous mantle. For this reason, in the frame of a wider research, two specific tests were carried out and at first, a ventilated roof was compared to a completely sealed one, then, the same ventilated roof was compared to a so-called laid roof in which the eaves and ridge lines were completely closed but the overlaps between tiles were not sealed to allow air entering and leaving. 
The results confirmed that the air permeability of a discontinuous roof plays a fundamental role in the improvement of the performances of the roof by reducing the temperatures under the cladding layer and therefore reducing the incoming heat flux and the energy demand for cooling.

\section{References}

1. UNEP - United Nations Environment Programme. 2020 global status report for buildings and construction (2020)

2. A. Gagliano, F. Patania, F. Nocera, A. Ferlito, A. Galesi, Energy Build., 49, 611 (2012)

3. M. Ciampi, F. Leccese, G. Tuoni, Sol. Energy, 79, 183 (2005)

4. A. Dimoudi, A. Androutsopoulos, S. Lykoudis, Energy Build., 38, 610 (2006)

5. D. Li, Y. Zheng, C. Liu, H. Qi, X. Liu, Sustain. Cities Soc., 22, 86 (2016)

6. L. Susanti, H. Homma, H. Matsumoto, Y. Suzuki, M. Shimizu, Energy Build., 42, 1337 (2010)

7. S. Lee, S.H. Park, M.S. Yeo, K.W. Kim, Build. Environ, 44, 1431 (2009)

8. M. Bottarelli, G. Zannoni, Proceedings of the 7th National Congress AIGE, UNICAL, (2013)

9. G. De With, N. Cherry, J. Haig, J. Build. Phys., 33, 171 (2008)

10. M. Bottarelli, M. Bortoloni, G. Zannoni, R. Allen, N. Cherry, Energy, 137, 391 (2017)

11. M. Bottarelli, G. Zannoni, M. Bortoloni, R. Allen, N. Cherry, Propuls. Power Res., 6, 134 (2017) 